$\xi=-1$

\title{
Buckling Analysis of Stiffened Panels Under Fuselage Bending
}

\author{
Neela Rajan.R.R ${ }^{1}$, Bino Prince Raja.D ${ }^{1}$, Ramanan.G $*^{2}$, Muthu Sherin. ${ }^{1}$ \\ ${ }^{I}$ Noorul Islam Centre for Higher Education, Kumaracoil, Tamilnadu, India-629180 \\ ${ }^{2}$ Department of Aerospace Engineering, ACS College of Engineering, Bangalore, Karnataka, India-560074 \\ *Corresponding author E-mail: gramanan1987@gmail.com
}

\begin{abstract}
The utmost important characteristics in aircraft design were the structure load and safety. One of the main part of an aircraft is Fuselage. Depending on mass scattering of fuselage, the inertia forces will change along the length of the fuselage. Fuselage tends to bend down about axis wing due to Inertia force scattering. This bend will generate tension in upper part of fuselage simultaneously fuselage bottom part will experience compression. This work reveals the issue of the compression buckling of stiffened panels in the bottom portion of the fuselage. A linear static analysis will be carried out on a part of fuselage structure with scattered inertia load. The panels with extreme compression load is recognized for buckling analysis. From static analysis, compression load acting on each panel can be extracted and buckling factor is discovered. MSC PATRAN and MSC NASTRAN are used for this study. From the value of Buckling Factor for both Global and Local analysis of fuselage with different cross-sections, it is clear that the design of the fuselage stiffened panel with ' $L$ ' and ' $Z$ ' cross-section is safe one.
\end{abstract}

Keywords: stiffened panels; fuselage; Buckling analysis.

\section{Introduction}

An aircraft is a complex structure. Each component has one or many functions and designed to guarantee that it can carry out those functions safely and without damaging [1]. But if the sheet is folded, it suddenly does have the ability to needs to be strong and stiff enough to withstand the exceptional circumstances [2]. These requirements, in most of the aircrafts, result in thin shell structures, where the outer surface or skin of the shell is usually supported by longitudinal stiffening members and transverse frames to enable it to resist bending, compressive and tensional loads without buckling. They are used to maintain the shape of the fuselage and to shorten the span of the stringers between supports in order to increase the buckling strength of the stringers [3]. A stiffened fuselage structure is consist of several panels which is stiffened [4]. Depending on the spacing and the size of the frames and stringers relative to the shell skin, bulking deflections could be developed within each shell panel. In first example, referred to skin buckling, line of connection between skin and frames rests virtually straight, with stringers showing only negligible radial movement. In second example, as overall buckling, involves variable radial displacement of stringers [5]. The foremost objective of the experiment is to effectively combine the methods involved in buckling and Finite Element Analysis (FEA) to predict the life of a fuselage. Finite Element (FE) is used as a tool to create the virtual model of the fuselage, perform a linear analysis and buckling analysis. In this paper on fuselage structure, we are going to perform buckling analysis to calculate bottom skin of wing is proficient of bearing the load [6].

\section{Finite Element Analysis}

A Finite Element Method (FEM) is used to get estimated solution to a problems ruled by elliptic partial differential equation (PDE) equations. The FEM transforms the elliptic PDE into algebraic equations set, that are simple to solve. The initial value problems which has hyperbolic or parabolic differential equation and initial conditions not completely solved by the FEM [7, 8]. The hyperbolic or parabolic differential equations contain one independent variables as time. The pre-processing task includes building geometric model from CATIA solid model and extracting geometry, building the finite element model, giving properties, setting boundary and loading conditions and finally, assembling elements into a connected structure. MSC NASTRAN is used to carry out the Analysis. The analysis stage simply solves for the unknown DoF, also stresses and reactions. In the post processing stage, the results are evaluated and displayed. 'Mesh Smoothing' enhances element shapes and overall mesh quality, by adjusting the location of mesh vertices. The material used here is Al 2024-T3. An Aluminium alloy, with Copper as the primary alloying element. The advantages are high strength to weight ratio and good fatigue resistance. After selecting the type of material model that best represents the behaviour of a material, build the material model by specifying the appropriate material properties. To manually input material property values, use Patran's Material Property application forms.

Table 1 Properties of Al 2024-T3 material

\begin{tabular}{cc}
\hline Properties & Values \\
\hline Young's Modulus & $73.15 \mathrm{Gpa}$ \\
Poisson's Ratio & 0.33 \\
UTS & $483 \mathrm{Mpa}$ \\
Yield strength & $345 \mathrm{Mpa}$ \\
\hline
\end{tabular}

Table 2 One -dimensional frames parameter

\begin{tabular}{ccc}
\hline Frames & Length $(\mathbf{m m})$ & Width $\mathbf{( m m})$ \\
\hline Top & 2 & 30 \\
Middle & 28 & 2 \\
\hline
\end{tabular}


Bottom

2

Structural loads and boundary conditions

In a structural analysis problem, generally trying to determine the response of a model to physical loading, or specific structural behavior such as frequency response or buckling. Some of the loads and boundary conditions may work with include force, pressure, velocity, inertial loads, displacement, temperature, and contact [9]. For the same load and BC's, the buckling analysis is made and repeated for various thickness of skin, till the buckling value decreases to minimum. Analysis is the gateway to the various solvers that can be used to analyze a model and generate results.

\section{Results of Local Buckling}

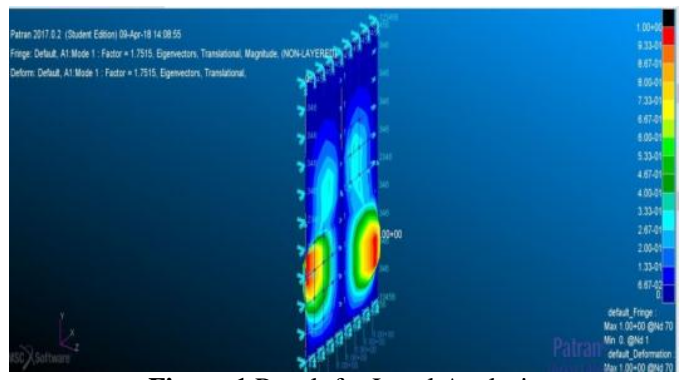

Figure 1 Result for Local Analysis

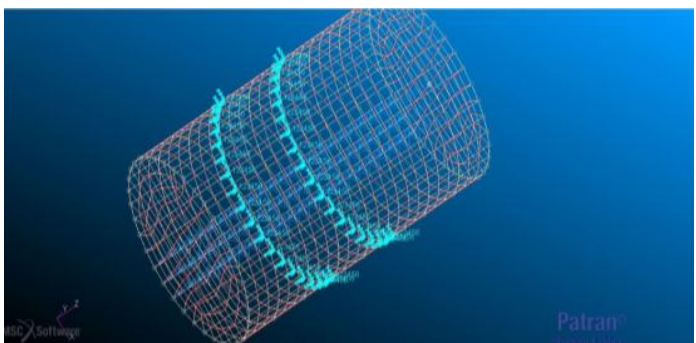

Figure 2 PATRAN model of fuselage structure

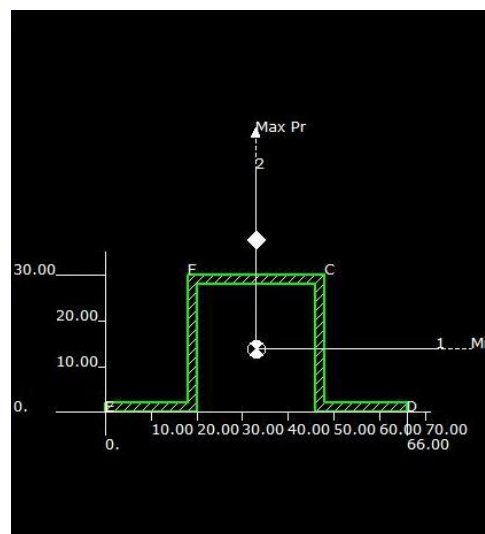

Fig 3 cross section of the longerons

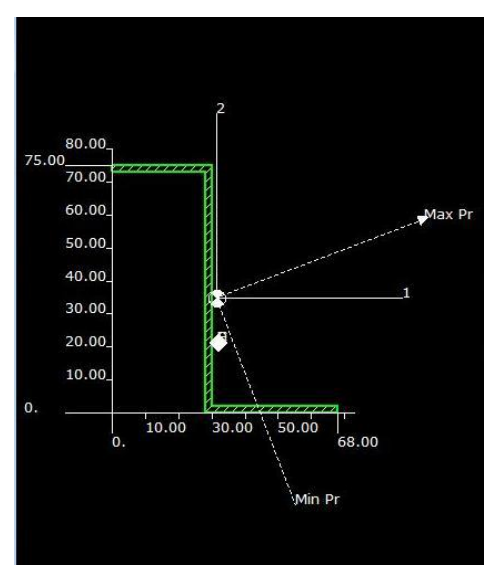

Fig 4 cross section of the frames

Al 2024-T351 is used in current Fuselage section due to high strength and fatigue resistance properties and the table 3 shows the more details. In a structural analysis problem, generally trying to determine the response of a model to physical loading, or specific structural behavior such as frequency response or buckling. Some of the loads and boundary conditions may work with include force, pressure, velocity, inertial loads, displacement, temperature, and contact.

Table 3 Material Properties

\begin{tabular}{cc}
\hline PROPERTIES & VALUES \\
\hline Young's Modulus & $73.15 \mathrm{Gpa}$ \\
Poisson's Ratio & 0.33 \\
Ultimate tensile strength & $483 \mathrm{Mpa}$ \\
Yield strength & $345 \mathrm{Mpa}$ \\
\hline
\end{tabular}

\subsection{Results of Buckling Analysis}

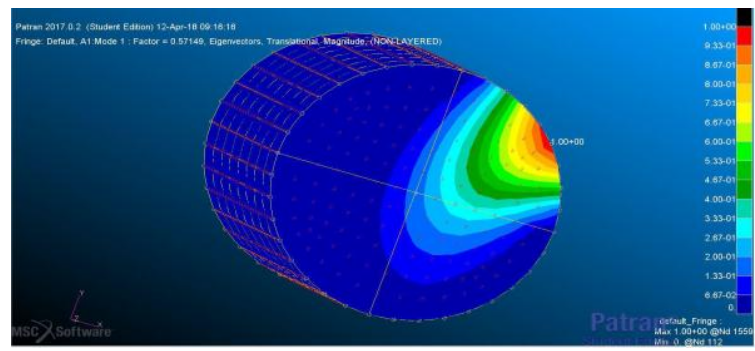

Fig 5 Buckling Factor for Eigenvectors Translational

From the buckling analysis the results of buckling factor of model is 0.5149 is shown in the fig 5 and fig 6 . The will be failed because of the critical load is less compared to the total load [10]. If B.F $<1$ structure will fail, B.F $=1$ structural modification is required and B.F $>1$ structure is safe. Here, we got Buckling Factor as 0.5149 , which is less than 1 . Hence, the structure will fail and so, we have to consider a new cross-section. After getting a low Buckling Factor, we have to change the cross-section of the longerons, from inverted ' $U$ ' cross-section to ' $L$ ' cross-section [11]. Then, following the same procedure, which we were using before. The dimensions of fuselage for the modelling of fuselage are shown in table 4. After modelling in PATRAN we get the fuselage model shown in fig. Likewise the dimensions of the longerons are shown in the table. The modified cross section of the longeron is shown fig 7 .

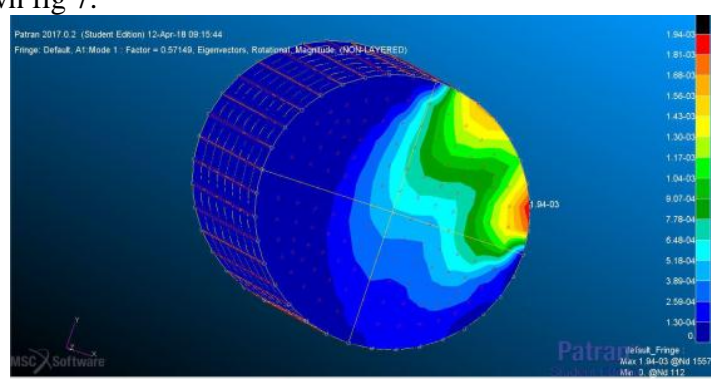

Fig 6 Buckling Factor for Eigenvectors Rotational 


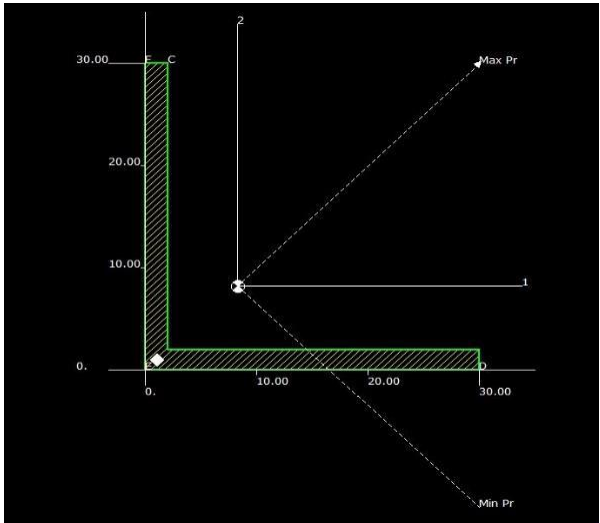

Fig 7 Modification of cross-section of longeron Table 4 Fuselage dimension

\begin{tabular}{cc}
\hline GEOMETRICAL PARAMETERS & DIMENSIONS \\
\hline Length & $7200 \mathrm{~mm}$ \\
Longerons length & $7200 \mathrm{~mm}$ \\
Frames diameter & $2280 \mathrm{~mm}$ \\
Aircraft Weight & $11740 \mathrm{Kg}$ \\
Wing span & $20000 \mathrm{~mm}$ \\
Skin thickness & $2 \mathrm{~mm}$ \\
\hline
\end{tabular}

Buckling Factor for Global analysis $=1.7123$

Buckling Factor for Local analysis $=1.7515$

Theoretical calculation for Local analysis $=1.7607$

By Linear static analysis we can get maximum compressive stress $1140 \mathrm{~kg} / \mathrm{mm}^{2}$. Then from buckling analysis obtained factor is 1.7123 the value greater to one which shows applied load is lesser than critical buckling load [12]. By Local buckling analysis, we observed buckling factor is 1.715 . The final value of buckling factor is in good correlation with theoretical value.

\section{Conclusions}

This work deals with the buckling analysis of the fuselage stiffened panel structure, on the basis of different cross-sectional view. The Buckling Analysis was done with the NASTRAN \& PATRAN software. From the initial cross-section of 'Inverted U shape', it was found out that some modification is needed on the cross-section of the fuselage members, to make it as a safe design. For that, gradually various cross-sections were considered and for different cross-sections, the analysis was carried out and finally obtained an optimum value of Buckling Factor (1.7515). Due to some limitations of the NASTRAN software, the distribution of stress between the stiffening members was not 'even'. From the value of Buckling Factor for both Global and Local analysis of fuselage with different cross-sections, it is clear that the design of the fuselage stiffened panel with ' $L$ ' and ' $Z$ ' cross-section is safe one.

\section{References}

[1] D.J. Dawe, S. Wang, "Postbuckling analysis of composite laminated panels", American Institute of Aeronautics and Astronautics Journal, 38 (2000)

[2] J.W. Hutchinson, W.T. Koiter, "Post buckling theory", Applied Mechanics Reviews, 23 (1970), pp. 1353-1366.

[3] T.M. Roberts, Z.G. Azizian, "Strength of perforated plates subjected to in-plane loading", Thin-Walled Structures, 2 (2) (1984), pp. 153-164.

[4] Yadav, Shatjit, and M. Ramachandran. "Analysis of Optimized Wind Turbine Failure Using Computational Fluid Dynamics." Materials Today: Proceedings 4, no. 2 (2017): 1788-1793.

[5] W.H. Wittrick, F.W. Williams, "Buckling and vibration of anisotropic or isotropic plate assemblies under combined loadings", International Journal of Mechanical Sciences, 16 (4) (1974), pp. 209. 239

[6] Ramanan.G, Neela Rajan.R, Diju samuel.G, Edwin Raja Dhas.J, "Multiple Response Characteristics Optimization of WEDM Pa- rameters for AA7075 composites by Response Surface Grey Relative analysis", International Journal of Mechanical Engineering and Technology. Vol.8, (2017), pp.667-676.

[7] D. Quinn, A. Murphy, W. McEwan, F. Lemaitre, "Stiffened panel stability behaviour and performance gains with plate prismatic substiffening", Thin-Walled Structures, 47 (2009), pp. 1457-1468.

[8] C. Bisagni and P. Cordisco, "Testing of Stiffened Composite Cylindrical Shells in the Post Buckling Range until Failure", American Institute of Aeronautics and Astronautics Journal, 42 (9), (2004), 1806-1817.

[9] Ramanan.G, Edwin Raja Dhas.J and Ramachandran.M, "Optimization of material removal rate and surface roughness for wire electric discharge machining of AA7075 composites using grey relational analysis", International Journal of Vehicle Structures and Systems, Vol.9, No.5 (2017), pp. 309-312.

[10] Rajesh Prabha.N, Edwin Raja Dhas.J and Ramanan.G., "Finite element structural analysis of connecting rod of AA7075-TiC composite using ANSYS", International Journal of Mechanical Engineering and Technology, Vol. 8, 2017, pp. 1102-1110.

[11] Ragavendran, U., Viral Mehta, Vishal Fegade, and M. Ramachandran. "Dynamic Analysis of Single Fold Symmetric Composite Laminates." International Journal of Civil Engineering and Technology 8, no. 11 (2017): 536-545.

[12] Christian Mittelstedt, "Explicit local buckling analysis of stiffened composite plates accounting for periodic boundary conditions and stiffener-plate interaction", Composite Structures, Vol. 91, No.3 (2009), pp.249-265.

[13] M. Lillico, R. Butler, G. Hunt, A. Watson, D. Kennedy and F.W. Williams, "Analysis and testing of a postbuckled stiffened panel", American Institute of Aeronautics and Astronautics Journal, 40 (5) (2002), pp. 996-1000.

[14] Patrick E.Fenner, Andrew Watson, "Finite element buckling analysis of stiffened plates with filleted junctions", Thin-Walled Structures, Vol.59 (2012), pp.171-180. 